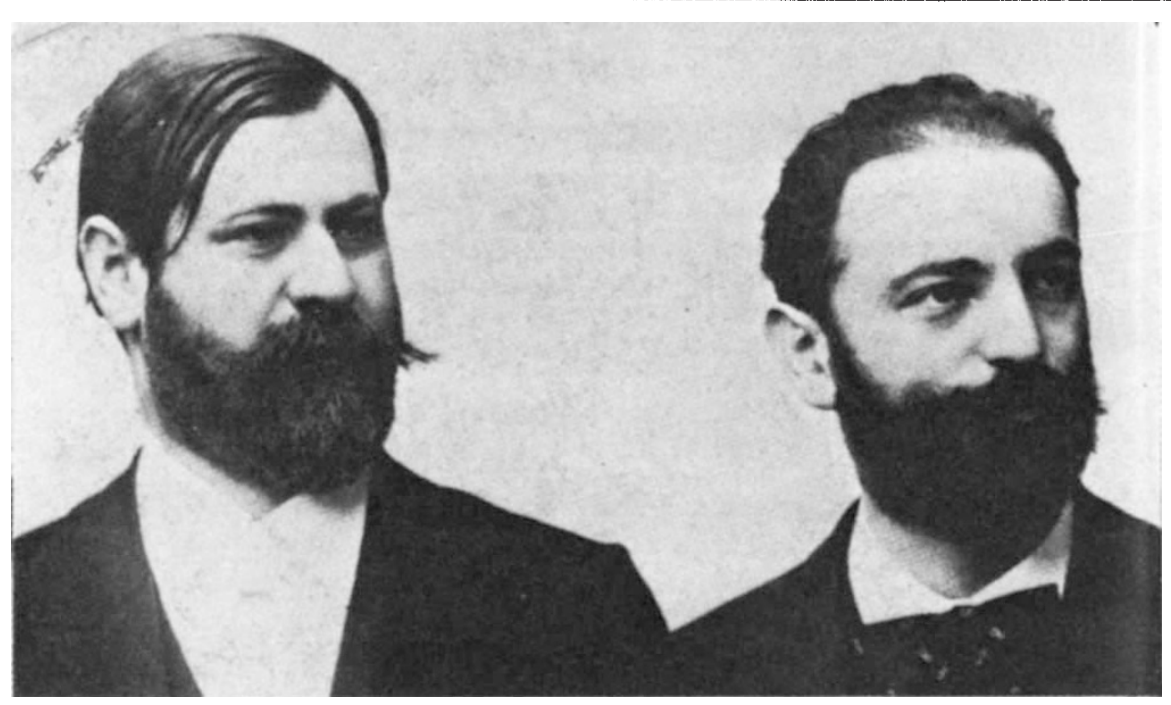

Freud (left) with Wilhelm Fliess, his confidant during the early years of psychoanalysis

little about the forces that motivate human action that the ultimate value of Freudian theory cannot be assessed. It is certain only that much of the theory remains vague and that Freud often overgeneralized: his concentration on the libido and the Oedipus complex as the main influences in the development of personality was mistaken. It is doubtful if present-day psychology would be much different had Freud never lived: his main influence has been on the patterns of thought of the layman and hence on much twentieth-century art and culture. Moreover, there are many who feel that Freud sent psychotherapy in a wrong direction, and that it has only recently

begun to recover from the damage done by his ideas. New therapeutic developments are much closer to Adlerian practice than to Freudian.

There are no pyrotechnics in Ronald Clark's new book, but he has made available in one place a mass of previously published material and has added some facts of his own discovery. Although he has not broken the enigma of Freud's personality, he has produced a highly professional biography.

Stuart Sutherland is Director of the Centre for Research on Perception and Cognition at the University of Sussex.

\title{
What is it that we know?
}

\section{D.V. Lindley}

\author{
The Enterprise of Knowledge: An Essay on \\ Knowledge, Credal Probability, and \\ Chance. By Isaac Levi. Pp.462. (MIT \\ Press: 1980.) \$27.50, £17.
}

A subSTANTIAL part of the knowledge of the world that we have today is the result of the activities of scientists. If knowledge is thought of as a tool by which we may control the world, then scientific thinking is pre-eminent. Artists may help our understanding, but it is scientists who develop the techniques and ideas of control. It is therefore surprising that scientists have paid so little attention to the appreciation of how knowledge is acquired and manipulated. Kuhn has pointed out that most scientific work consists of following through a standard set of techniques, or paradigms, and that the individual is so absorbed in the technicalities of the apparatus, the field, or the mathematics, that he never needs to think about the basis of what he is doing. Other scientists, a small but significant minority, do think more widely but again are statisticians and most philosophers now agree upon: the description of our knowledge, and the way that knowledge is used in control, are essentially probabilistic. There are, however, substantial differences on how probability is to be used and what it means. The accepted paradigm of statistics uses probability only in the sense of frequency, so that we may speak of the probability of the experimental results, which may be repeated, but not of the probability of the hypotheses, which cannot. A minority of statisticians, and perhaps the majority of philosophers, think of probability as a direct descriptor of knowledge, so that probabilities of hypotheses are admitted. Some think of this probability as subjective, some as objective. Here philosophy is providing usable, and - it is to be hoped - useful, results; scientists ought to take note.

In this book, Isaac Levi talks of what he chooses to call credal probability as the way of evaluating hypotheses. Knowledge is thought of, not as a collection of results, but as an input to rational decision-making - "Epistemologists ought to care for the improvement of knowledge rather than its pedigree"'. The same should be true of scientists. Levi is thus no scholar isolated from practice, but a scholar who is concerned with application as the basis of our thinking. (An appendix discusses the use of his ideas in assessing accident risks in nuclear power plants.)

He therefore disagrees with most statisticians' view of probability as only frequentist - in such situations he talks of "chance" - and devotes a fair portion of the book to a criticism of the methods they have developed, paying special attention to Fisher's concept of fiducial probability, a concept that exerts a fascination out of all proportion to its value. His view is the Bayesian one that probability applies to all uncertainty, not just to repeatable phenomena; so that we can speak of the probability of isolated events, or of hypotheses. What Levi calls a "strict" Bayesian, says this probability is unique and definite, and expresses the totality of our knowledge. In conjunction with utility (which receives little discussion in the book) decisions can be made by maximizing expected utility. Levi does not agree with this uniqueness and admits a set of probabilities. This leads to a difficulty, since the existence of many probabilities leads to many expected utilities, and choice between them has to introduce other considerations. He uses a maximin device in which the worst possible outcome is made as attractive as possible. (It is a pity he does not discuss the objections to maximin that exist, especially as he uses a restricted form of that criterion to which they may not apply.)

Levi writes as a philosopher and the emphasis in his treatment is on the ideas rather than their execution. He discusses at length the related ideas of other 
philosophers, especially Kyburg and Hacking who have written on probabilistic ideas and is critical of Popper's appreciation of scientific knowledge. And yet his treatment is often realistic, since it is always set against this decision-making, operational background. Thus he criticizes the adherents of the likelihood view, and Shackle in particular, by saying:

The point is, that calling a mode of appraisal a way of measuring or assessing support is not helpful. A specification of the use or function of the mode of appraisal in inquiry and deliberation is needed, whether the method is probabilistic or not.

This is not an easy book to read. It is very long and parts of it are rather technical. For someone concerned with logical questions, his definitions are not as crisp or as clearly laid out as one might wish. There are many parts where the language is turgid; this is his definition of L-irrelevant:

the information that a trial is of kind $T$ is $L$-irrelevant to the issue as to whether an $\mathrm{R}$ occurs on that trial relative to information that the trial is of kind $S$ if and only if $\mathrm{K}$ contains the information that being of kind $T$ is stochastically irrelevant to yielding an $\mathrm{R}$ on a trial of kind $\mathrm{S}$.

A more serious point of style that disturbs me is his failure to help the book's readability by adopting standard notation. For example, experts in the probability calculus use $p(A / B)$ for the probability of A given $B$. Whey then use $Q(h ; e)$ ? And why use irrelevant instead of independent? Much of the later sections of the book are difficult going because of the apparently unnecessary changes of language and notation.

It is a pity that Levi has so little to say about works of the "strict" Bayesians, de Finetti, Jeffreys, Savage, Ramsey and others. Is he fully aware of the basic result that a man who is to act sensibly can only do so if he acts in accordance with a unique probability and a unique utility? And why is there no mention of exchangeability, that brilliant notion expounded by de Finetti in his two-volume treatise Theory of Probability (Wiley, 1974/5), that connects chance with belief and embraces the frequentist framework within that of knowledge? Levi says in his discussion of nuclear safety, that "the available evidence fails to warrant a sufficiently definite system of credal probability judgments"; but probability is the only description of the available evidence, as Ramsey and others have shown. We may not like the evidence, but probability should not be the scapegoat.

Where does this book stand as a contribution to the study of knowledge? Its importance lies in its new emphasis on a general, credal probability and in its forward-looking, decision-orientated view of knowledge. It leads us further along the road towards a philosophically satisfying, yet usable, appreciation of scientific method: an appreciation that could do much in a really practical way to assist the development of science and technology. And yet, is that not already with us in the work of the "strict" Bayesians? It is to be hoped that scientists will think about these issues, and read de Finetti and Jeffreys as well as Levi.

D.V.Lindley was formerly Professor of Statistics and Head of the Department of Statistics and Computer Science at University College London.

\section{Fit for mankind: a vision of Earth}

\section{Paul A. Colinvaux}

The Wooing of Earth. By René Dubos. Pp.183. (Athlone/Scribner's: 1980.) £7.50, \$8.95.

To woo the Earth means to coax our countrysides into the human image of what the good Earth should be. And the image is often very good; a land fair and open, contrived to reflect an ancient savanna where our speices was moulded by evolution, long, long ago. We have done this everywhere and the carpers among us are wrong to call our doings bad. This is the Dubos message of good cheer.

Europe is beautiful, with its vistas of villages, pastures and trees. The European wilderness of the old times, where immense, dark forest forever hid the view, was a frightening place. Greece is delightful, even though its shimmering hillsides are only kept bare by relentless overgrazing. New Englanders like their patterns of village and farm, and their legislators are trying to stop land going back to forest as farms are abandoned. Lovely parklands like the Han dynasty Summer Palace or the creations of Capability Brown are not wilderness but nature contrived to fit the human appetite. Hardly any of us want wilderness. Why not admit this - and be optimistic about how we can change the Earth without ruining it.

Dubos points out that the sainted Thoreau had a comfortable time at Walden Pond, close to the safety of tranquil Concord, and that the sight of a real wilderness of trees in Maine shocked him to hasty retreat. We pay lip service to the wilderness, but most still turn away from its frightening possibilities. We urge Africans to save the game herds, but the Africans will destroy them before the year 2000 because farm land is better than wilderness supporting wild beasts. This seems so self-evident that I have long marvelled at the hopes of those who thought the Serengeti would be saved. We

\section{New books from IRL}

\section{Nucleic Acids \\ Synthesis:}

Applications to Molecular Biology and Genetic Engineering

Proceedings of the International Symposium on Chemical Synthesis of Nucleic Acids. Held May 1980 in Egestorf, West Germany.

Nucleic Acids Symposium Series No. 7.

In the fields of molecular biology and genetic engineering, synthetic nucleic acids and their constituents have proved to be valuable tools and their uses appear to be infinite. in the present era of 'synthetic biology' it is not surprising that the chemical synthesis of nucleic acids is experiencing a tremendous renaissance. Thus, it was most opportune that this conference, organized by Hubert Köster, should have been held, and the list of participants reads like a 'Who's Who' in the field, together with representatives from industry. This issue of the Nucleic Acids Symposium Series contains details of the latest methods in oligonucleotide synthesis from practicaliy all the leading laboratories in the world including those laboratories in pre wold, including those or Eastern Europe, Japan and China and serves as a source not only of their curren (and usually unpublished) research, but also of their predictions for the future of the methodology and the use of such oligonucleotides.

396 pp ISBN 0904147266 (Hard) August 1980 £17.00/US\$40.00

Obesity: A Bibliography 1974-1979

340 pp ISBN 0904147177 (Hard) 乏22.50NS $\$ 55.00$

October 1980

\section{Olfaction and Taste VII}

Proceedings of the Seventh Internationa Symposium on Olfaction and Taste and Fourth Congress of the European Chemoreception Research Organisation. Held July 1980 in the Netherlands. 500 pp ISBN 0904147207 (Hard) $£ 22.00$ NS $\$ 50.00$

November 1980

\section{Immunology of the Eye} Workshop 1:

Immunogenetics and Transplantation Immunity

Proceedings of a Workshop on Immunogenetics and Transplantation Immunity. Heid December 1979 in

Chantilly, Virginia.

Edited by George M. Steinberg, Igal Gery and Robert $B$. Nussenblatt

286 pp ISBN 0904147258 (Soft) $£ 10.00$ NS $\$ 25.00$

November 1980

Forthcoming Proceedings in the Immunology of the Eye Workshop Series

Autoimmune Phenomena Infection, Inflammation and Allergy

\section{IRL Information Retrieval}

1 Abbey St., Eynsham

Oxford OX8 $1 \mathrm{~J}$, England

Suite 815, Fisk Building.

250 West 57 th Street. New York NY 10019, U.S.A. 